The best results were obtained when treatment was started in early infancy.

Sometimes surprisingly good results occurred in older children, with a rise in incelligence level which enabled them to go to a school for the educationally subnormal or to a normal school.

All but three of the 18 children with epilepsy responded badly to dietary treatment.

There was no evidence that dietary treatment resulted in poor physical development.

Thanks are due to the physicians at the hospital for permission to study their patients ; to Mr. H. Goldstein for help with the statistical analysis; to the staff of the Department of Psychological
Medicine for their interest in the psychometric testing; and to the dietitians and ward staff for their co-operation in the treatment of the patients. We are grateful to the Nuffield Foundation for financial assistance.

\section{REFERENCES}

Coates, S., Norman, A. P., and Woolf, L. I. (1957). Ibid., 32, 313. Clayton, B., Francis, D., and Moncrieff, A. (1965). Brit. med. Ұ., 1, 54. -Moncrieff, A. A., Pampiglione, G., and Shepherd, J. (1966). Arch. Dis. Childh., 41, 267.

Moncrieff, A., and Wilkinson, R. H. (1961). Ibid., 1, 763.

Moncrieff, A., and Wilkinson, R. H. (1961). Ibid., 1, 763.

Medical Research Council (1963). Brit. med. F." 1, 1691 . Record. London.

Woolf, L. I., Griffiths, R., and Moncrieff, A. (1955). Brit. med. F., 1, 57. 33, 31. Coates, S., and Dillistone, F. (1958). Arch. Dis. Childh.

\title{
Studies in the Epidemiology of Tinea Pedis. VIII: Fungal Infection in a Long-stay Hospital
}

\author{
MARY P. ENGLISH,* M.SC.; R. R. WETHERED, † B.A., B.M., в.CH. ; ETHEL H. L. DUNCAN, M.A., B.sc.
}

\author{
Brit. med. F., 1967, 3, 136-139
}

Tinea pedis has been studied in many different types of community, each yielding diflerent but complementary information about the epidemiology of the disease. It now seems certain that the most common means of transmission is the direct contact of healthy feet with small fragments of skin shed by infected persons (Gentles, 1957 ; English and Gibson, 1959b; Gip, 1966). This may happen in various ways, the relative importance of which will differ in different communities. It is also known that the incidence of infection is higher in persons living a communal life (Marples and di Menna, 1949 ; English, Gibson, and Warin, 1961 ; Wrede, 1965) or using communal washing facilities or swimming-baths (Tritsmans and Vanbreuseghem, 1955 ; Gentles and Holmes, 1957 ; English, Gibson, and Duncan, 1960) than in those not doing so; and that, in children, incidence rises with age (English and Gibson, 1959a ; Munro-Ashman and Clayton, 1962 ; Polemann, 1955). There is dispute about the extent to which fungi are carried on, and hence dispersed by, lesion-free feet (Rosenthal, Baer, Litt, Rogachefsky, and Furnari, 1956 ; English, 1962). That many people have a natural resistance to the disease is a constantly observed fact, though the nature of this resistance and the proportion of the population protected by it are unknown.

The two fungi responsible for the overwhelming majority of cases of tinea pedis in this country are Trichophyton interdigitale and $T$. rubrum. The incidence of $T$. rubrum is increasing rapidly, and recent figures from dermatological clinics in Bristol show that it now occurs more often in them than $T$. interdigitale. However, English and Gibson (1959a) and English et al. (1961) have shown that both in day schools and in boarding-schools $T$. interdigitale was by far the most common fungus, and this has been confirmed in another boarding-school by Munro-Ashman and Clayton (1962). Similar figures for a sample of the adult population not attending skin clinics are not available, but English and Turvey (work to be published) have recently shown that in patients attending a chiropody clinic, almost entirely for complaints other than tinea pedis, 20 of the 33 infections found were attributable to $T$. interdigitale and only five to T. rubrum. T. interdigitale, there-

\footnotetext{
- Mycologist, Bristol Royal Hospital.

+ General Practitioner, Bristol.

¥ Senior Lecturer in Medical Statistics, University of Bristol.
}

fore, is still the most common cause of tinea pedis in the population at large. Epidermophyton floccosum, the third causal organism, is comparatively rare and its incidence seems to be changing little. The clinical manifestations and epidemiology of these three species differ, but only very tentative suggestions regarding the reasons for this have been put forward.

It seemed possible that information on some of the above points might be provided by the study of a large, relatively stable community of adults living communally for most or all of their lives. During 1964 the attention of one of us (R. R.W.) had been attracted by the large number of patients in one section of a long-stay hospital for mentally retarded men who had clinically severe tinea pedis, and it was decided that a detailed epidemiological study of this hospital should be undertaken.

\section{Subjects}

The hospital housed some 400 male patients of all degrees of mental subnormality, some of whom also had mild to severe physical handicaps.

Patients were grouped in "lodges," each housed in separate buildings or parts of buildings. Lodge 7, the largest, was also used for the supervision and discipline of difficult patients, and it was therefore likely that patients from most other lodges spent periods there. Other transfers between lodges occurred at intervals, but many patients had been in the same lodge for a very long time. Lodge 9 was reserved for the elderly sick.

Lodges 7 and 8 each had a 60-bed dormitory; other dormitories ranged in size from 6 to 24 beds. Bathrooms were communal and each contained a number of baths. Up to the end of 1964 one bathroom served lodges 1-5, another lodges 6-8, and lodge 9 had its own. In December of that year additional bathrooms were brought into use so that one was shared by lodges 1 and 2, another by lodges 3-5, and lodges 6, 7 , and 8 had one each.

Of the 358 patients included in the survey, 7 were under 20 years old and $276(77 \%)$ were over $40 ; 326(91 \%)$ had lived in the hospital for three years or more and $236(66 \%)$ for 11 years or more. 
Patients were bathed twice weekly, clean socks and towels being issued after each bath. Towels were likely to be shared and used as bath mats; socks (which were all woollen) were not shared between launderings, but patients did not have their own towels or socks, which were laundered centrally and reissued indiscriminately. Each patient had his own slippers or house shoes, but these were not marked, as were other clothes. In fact, patients rarely wore them and often walked sbout in the dormitories bare-footed.

\section{Clinical, Laboratory, and Statistical Methods}

Scrapings were taken from 358 patients during the summer of 1965 by two of us (M.P. E. and R. R. W.) with the assistance of two registrars in dermatology. Patients omitted from the survey were either on licence or on holiday. Clinical details were taken down by nurses from the hospital. The feet and hands of all patients were examined and samples taken from all lesions of skin or nails which might possibly be attributed to fungal infection; if there were no such lesions, or if only nail lesions were found, scrapings were taken from webs between the fourth and fifth toes.

Details of the patient's age, length of residence at the hospital, lodge, physical capability, abnormalities, etc., were collected by the hospital's nurses from the patients' notes.

Laboratory investigations were carried out by M.P.E. Scrapings were cultured the day after they were taken. All were plated on glucose-peptone agar with chloramphenicol and cycloheximide and incubated for at least one week at $29^{\circ} \mathrm{C}$. ; further fragments of those from which no dermatophytes grew were then examined microscopically in $20 \%$ potassium hydroxide. In a number of cases in which a fungus was seen on microscopy but cultures had failed it was possible to obtain fresh scrapings from which the fungus was successfully isolated.

Nails which were positive on microscopy but not in culture were examined for non-dermatophyte fungi by replating them on cycloheximide-free medium, but were regarded as infected by these fungi only if at least $5 / 20$ inocula yielded the same organism.

Cultures from patients' socks were made (1) by shaking or scraping them over plates of glucose-peptone-cyclohexamidechloramphenicol agar (Broughton, 1955) and (2) by soaking small pieces of the fabric in the cooled molten medium and pouring-plates. Both methods were satisfactory.

The planning of the survey and the analysis of results were the responsibility of the third author (E.H.L.D.). The questionary used for recording patients' histories and laboratory and clinical findings was prepared in such a way that the replies could be used for punched-card analysis without further coding.

\section{Mycological and Clinical Results}

Table I shows the number of patients infected with each fungus or pair of fungi, and also the number of isolations of each organism. T. interdigitale was the dominant species, but a high percentage of $T$. rubrum was also recorded; $\boldsymbol{E}$. floccosum was comparatively rare. Isolates of $T$. interdigitale varied considerably in appearance, but the variations were not constant on subculturing. T. rubrum isolates, on the other hand, were almost all of the same distinctive type, which remained constant over many subcultures. The strain was very strongly pigmented and was unusual in being intermediate between the "granular" and "downy" types (English, 1964). All non-dermatophytes were found in toe-nails; that there were no Aspergillus spp. is unexpected (Walshe and English, 1966). The culture failure rate of $7.5 \%$ was well within normal limits.
TABLB I.-Incidence of Infections and Number of Isolations Amlong 358 Patients Examined

\begin{tabular}{|c|c|c|c|c|}
\hline \multirow[b]{2}{*}{ Fungus } & \multicolumn{2}{|c|}{ Persons Infected } & \multicolumn{2}{|c|}{ Isolations } \\
\hline & No. & $\begin{array}{c}\% \text { of Total } \\
\text { Persons Infected }\end{array}$ & No. & $\begin{array}{c}\% \text { of } \\
\text { Total } \\
\text { Isolations }\end{array}$ \\
\hline 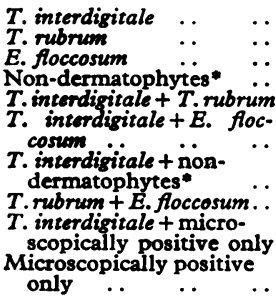 & $\left.\begin{array}{r}73 \\
38 \\
1 \\
6 \\
12 \\
2 \\
1 \\
1 \\
1\end{array}\right\} 17$ & $\left.\begin{array}{r}50 \cdot 0 \\
26 \cdot 0 \\
0 \cdot 7 \\
4 \cdot 1 \\
8 \cdot 2 \\
1 \cdot 4 \\
0 \cdot 7 \\
0.7 \\
0 \cdot 7\end{array}\right\} 11 \cdot 7$ & $\begin{array}{r}89 \\
51 \\
4 \\
7 \\
- \\
- \\
- \\
- \\
- \\
12\end{array}$ & $\begin{array}{r}54 \cdot 6 \\
313 \\
2 \cdot 5 \\
4 \cdot 3 \\
- \\
- \\
= \\
- \\
7 \cdot 4\end{array}$ \\
\hline Total & 146 & $40 \cdot 8$ & 163 & \\
\hline
\end{tabular}

All from toe-nails. Scopulariopsis brevicaulis, 2 isolates; Fusarium sp.;
Cephalosporium sp., 1 isolate; Penicillium sp., 1 isolate; cultures failed, 2.

Double infections, either concurrent or combined (Partridge, 1952), were found in $17(11.7 \%)$ of infected patients, and their occurrence was not related to the length of the patient's stay in hospital, his age, or the incidence of fungi in his lodge, all factors affecting opportunity for cross-infection. This contrasts with the observations of Gentles and Holmes (1957) in coal miners, and suggests that lack of resistance in the patient may also be a factor in the occurrence of double infections.

Table II shows the sites infected by dermatophytes only. The hands were involved in 6 out of 140 patients with tinea pedis ; in addition, one patient had also had a widespread infection with $T$. rubrum the previous year, which had responded to treatment. Nurses reported that groin infections, which they would probably notice while bathing patients, were not very common; if this was so it was unexpected in vie's of the high incidence of $T$. rubrum in the feet (English and La Touche, 1957) and the common occurrence of tinea cruris in all-male communities.

TABLE II.-Sites of Infection (excluding non-dermatophytes) Among 358 Patients Examined

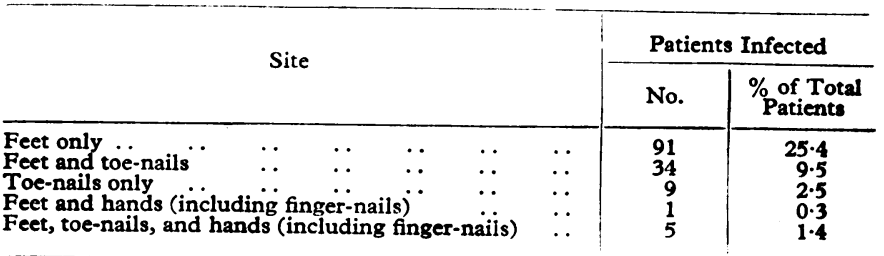

The clinical behaviour of $T$. interdigitale and $T$. rubrum is compared in Table III. The results confirm the observations of others that $T$. rubrum tends to cause extensive infections while those of $T$. interdigitale are more restricted. Toe-nails were involved in 19 out of $89(21 \%) T$. interdigitale infections and 21 out of $51(41 \%)$ T. rubrum infections: in 3 out of 19 cases of $T$. interdigitale infections of this site the skin of the feet was not affected, but all T. rubrum infections of the toe-

TABLE III.-Comparison of Extent of Infection by $T$. interdigitale and T. rubrum (double infections counted twice)

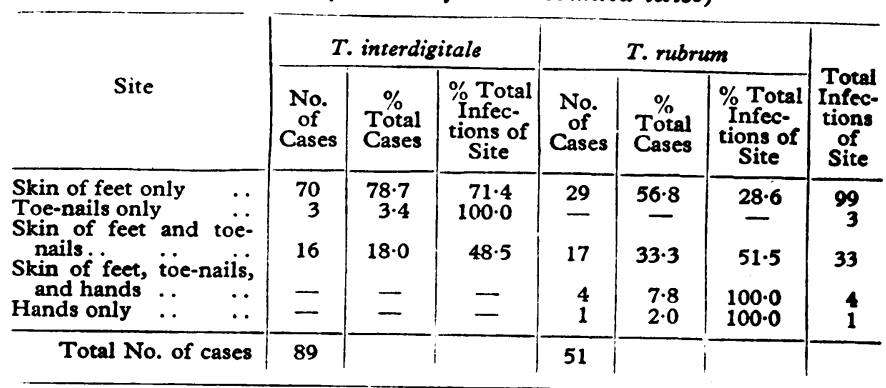


nails were part of a more widespread condition. All hand infections were attributable to T. rubrum.

Dermatophytes were present in the lesion-free toe-webs of 19 patients ; 17 of these had T. interdigitale, one T. rubrum, and one a fungus found on microscopy only. Three of the $T$. interdigitale infections were associated with clinical onychomycosis caused by the same fungus, and here the nails were obviously the source of contamination. The great preponderance of $T$. interdigitale over $T$. rubrum (Götz, Sturde, and Hantschke, 1965) probably reflects the comparatively mild nature of infections due to the former fungus and perhaps a tendency to spontaneous resolution. The occurrence of lesionfree infections was unrelated to the age of the patient, the length of his stay in hospital, or the incidence of infections in his lodge.

In view of the differences of opinion on the importance of lesion-free carriers in the epidemiology of tinea pedis, 17 of the above patients were re-examined after one year: 10 were found to be still infected, but to have developed lesions; six were no longer infected; and one ( $T$. interdigitale) remained infected without lesions. Most cases of apparent toe-web "carriers," therefore, were probably simply stages in the onset or regression (Svendsen, 1961) of an infection, or contamination from a clinical infection of the nail ; only one patient out of 358 could be regarded as a carrier in the usual sense. This is a lower rate than that found by Götz and Hantschke (1965) in a similar investigation on coal miners. These workers reported that 41 out of 1,240 (3\%) carried dermatophytes asymptomatically over a period of a year ; they do not, however, state whether any of these men had toe-nail infections.

\section{Epidemiological Results}

Table IV shows that the incidence of infection varied very appreciably from lodge to lodge. However, probability tests showed that for $T$. interdigitale all such interlodge variation could have occurred by chance; for $T$. rubrum only, the incidence in lodge 7 was significantly different from that in other lodges $(\mathrm{P}<0.05)$, and, for the total fungi, the incidence in lodge 1 was significantly higher than in other lodges $(\mathbf{P}<0.01)$. The ratio \% T. rubrum $/ \% T$. interdigitale for lodge 7 was $1 / 0.95$; that for all other lodges combined was $1 / 1.91$-that is, the proportion of $T$. rubrum infections in lodge 7 was significantly higher than that in other lodges $(P<0.05)$. There was no significant difference in average incidence in patients using different bathrooms, either when grouped according to bathrooms in use up to and during 1964 (Table IV) or when the new bathrooms in use after this date were considered.

TABLE IV.-Incidence of Infection in Lodges (excluding non-dermatophytes). Double Infection with $T$. interdigitale and $T$. rubrum Recorded in Both Columns $A$ and B; Column C Shows Total Number of Infected Patients

\begin{tabular}{|c|c|c|c|c|c|c|c|c|c|}
\hline \multirow{2}{*}{\multicolumn{2}{|c|}{ Lodge }} & \multicolumn{2}{|c|}{\begin{tabular}{c|}
$\mathrm{A}$ \\
$T$ inter- \\
digitale \\
Infections
\end{tabular}} & \multicolumn{2}{|c|}{$\begin{array}{c}\text { B } \\
\text { T. rubrum } \\
\text { Infections }\end{array}$} & \multirow{2}{*}{$\mid \begin{array}{c}T . \text { rubrum/ } \\
\text { T. inter- } \\
\text { digitale } \\
\text { Ratio }\end{array}$} & \multicolumn{2}{|c|}{$\begin{array}{c}\text { C } \\
\text { All derma- } \\
\text { tophyte } \\
\text { Infections } \\
\end{array}$} & \multirow{2}{*}{$\begin{array}{c}\text { Total } \\
\text { Patients } \\
\text { in } \\
\text { Lodge }\end{array}$} \\
\hline & & No. & $\%$ & No. & $\%$ & & No. & $\%$ & \\
\hline \multirow[t]{2}{*}{$\left.\begin{array}{l}1 \\
2 \\
3 \\
4 \\
5\end{array}\right\}$} & $\begin{array}{l}\text { Bathroom shared } \\
\text { till Dec. } 1964\end{array}$ & \begin{tabular}{|r|}
9 \\
9 \\
11 \\
9 \\
3 \\
\end{tabular} & $\begin{array}{l}37.5 \\
20.5 \\
39.4 \\
23.1 \\
11.5 \\
\end{array}$ & $\begin{array}{l}5 \\
4 \\
4 \\
6 \\
2\end{array}$ & $\begin{array}{r}20.8 \\
9.1 \\
14.3 \\
15.4 \\
7.7 \\
\end{array}$ & $\begin{array}{l}1 / 1 \cdot 8 \\
1 / 2 \cdot 3 \\
1 / 2 \cdot 8 \\
1 / 1 \cdot 5 \\
1 / 1 \cdot 5\end{array}$ & $\begin{array}{r}16 \\
12 \\
13 \\
14 \\
5\end{array}$ & $\begin{array}{l}66.6 \\
27.3 \\
46 \cdot 4 \\
35.6 \\
19 \cdot 2 \\
\end{array}$ & $\begin{array}{l}24 \\
44 \\
28 \\
39 \\
26 \\
\end{array}$ \\
\hline & Total .. & 41 & $25 \cdot 5$ & 21 & 13.0 & & 60 & $37 \cdot 3$ & 161 \\
\hline \multirow[t]{2}{*}{$\left.\begin{array}{l}6 \\
7 \\
8\end{array}\right\}$} & $\begin{array}{c}\text { Bathroom shared } \\
\text { till Dec. } 1964\end{array}$ & $\begin{array}{r}7 \\
18 \\
15 \\
\end{array}$ & $\begin{array}{l}26 \cdot 0 \\
22 \cdot 2 \\
25 \cdot 4 \\
\end{array}$ & $\begin{array}{r}2 \\
19 \\
6 \\
\end{array}$ & $\begin{array}{r}7.4 \\
23.4 \\
10.2 \\
\end{array}$ & $\begin{array}{l}1 / 3 \cdot 5 \\
1 / 1 \cdot 9 \\
1 / 2 \cdot 5 \\
\end{array}$ & $\begin{array}{r}99 \\
35 \\
\end{array}$ & $\begin{array}{l}33.3 \\
43.2 \\
37.3\end{array}$ & $\begin{array}{l}27 \\
81 \\
59\end{array}$ \\
\hline & Total .. & 40 & $24 \cdot 0$ & 27 & $16 \cdot 2$ & & 66 & 39.5 & 167 \\
\hline \multirow[t]{2}{*}{9} &.. & 8 & $26 \cdot 7$ & 3 & $10 \cdot 0$ & $1 / 2 \cdot 7$ & 14 & 46.7 & 30 \\
\hline & Grand total $\ldots$ & 89 & $24 \cdot 9$ & 51 & $14 \cdot 2$ & $1 / 55$ & 140 & $39 \cdot 0$ & 358 \\
\hline
\end{tabular}

Figures in italics are statistically significant (see text).
Other factors investigated and found to be unrelated to the incidence of infection were size of dormitory, patient's age, mongolism, deformities of the feet (Svendsen, 1961), and mobility. With regard to mobility, it was found that of nine patients who had been unable to walk from birth, four had tinea pedis.

A long stay in hospital was found to increase significantly the likelihood of infection. Of 31 patients who had been in residence for under three years, $6(19 \%)$ were infected; while of 327 who had been in residence for a longer period 134 (41\%) were infected $(P=0.02)$.

Hyperhidrosis appeared to inhibit fungal infection, for none of the 12 hyperhidrotic patients had the disease $(P=0.00164$ by Fisher's exact probability test).

\begin{tabular}{|c|c|c|c|c|c|c|c|}
\hline \multirow[t]{2}{*}{$\begin{array}{l}\text { Age in } \\
\text { Years }\end{array}$} & \multicolumn{2}{|c|}{$\begin{array}{c}T . \text { interdigitale } \\
\text { Infections }\end{array}$} & \multicolumn{2}{|c|}{$\begin{array}{l}\text { T. rubrum } \\
\text { Infections }\end{array}$} & \multicolumn{2}{|c|}{$\begin{array}{c}\text { All Fungal Infec- } \\
\text { tions Including } \\
\text { Non-dermato- } \\
\text { phytes }\end{array}$} & \multirow{2}{*}{$\begin{array}{c}\text { No. of } \\
\text { Patients } \\
\text { Examined }\end{array}$} \\
\hline & No. & $\%$ & No. & $\%$ & No. & $\%$ & \\
\hline $\begin{array}{l}\text { Under } 50 . . \\
50 \text { and over }\end{array}$ & $\begin{array}{r}5 \\
14\end{array}$ & $\begin{array}{l}3 \cdot 0 \\
7 \cdot 3\end{array}$ & $\begin{array}{r}4 \\
17\end{array}$ & $\begin{array}{l}2 \cdot 4 \\
8 \cdot 8\end{array}$ & $\begin{array}{l}18 \\
37\end{array}$ & $\begin{array}{l}10 \cdot 9 \\
19 \cdot 3\end{array}$ & $\begin{array}{l}165 \\
193\end{array}$ \\
\hline Significance & \multicolumn{2}{|c|}{ Not significant } & \multicolumn{2}{|c|}{$P<0.02$} & \multicolumn{2}{|c|}{$P<0.05$} & \\
\hline
\end{tabular}

Toe-nail infections were found to be unrelated to the length of the patient's stay in hospital, but those due to T. rubrum and total fungi (including non-dermatophytes) were significantly related to the patient's age (Table V) (Rosman, 1966 ; Walshe and English, 1966). The incidence of onychomycosis due to T. rubrum was significantly higher in lodge 7 than in all other lodges, but that of $T$. interdigitale onychomycosis was not (Table VI).

\begin{tabular}{|c|c|c|c|c|c|c|}
\hline \multirow{2}{*}{\multicolumn{2}{|c|}{ Lodge }} & \multicolumn{2}{|c|}{$\begin{array}{c}T . \text { interdigitale } \\
\text { Infections }\end{array}$} & \multicolumn{2}{|c|}{$\begin{array}{l}\text { T. rubrum } \\
\text { Infections }\end{array}$} & \multirow{2}{*}{$\begin{array}{l}\text { No. of } \\
\text { Patients }\end{array}$} \\
\hline & & No. & $\%$ & No. & $\%$ & \\
\hline 7 Ali others & $\therefore$ & $\begin{array}{r}5 \\
14\end{array}$ & $\begin{array}{l}6 \cdot 2 \\
5 \cdot 1\end{array}$ & $\begin{array}{r}9 \\
12\end{array}$ & $\begin{array}{r}11 \cdot 1 \\
4 \cdot 3\end{array}$ & $\begin{array}{r}81 \\
277\end{array}$ \\
\hline Significance & . & \multicolumn{2}{|c|}{ Not significant } & \multicolumn{2}{|c|}{$P<0.05$} & \\
\hline
\end{tabular}

Cultures were made (1) from one pair of socks from each of three patients with $T$. interdigitale infection and one pair from a patient with $T$. rubrum infection after they had been worn for four days and (2) from another pair of socks from each of the same patients after these had been worn for four days and washed in the hospital laundry. The appropriate fungus was recovered from all the unlaundered socks, and a few colonies of $T$. interdigitale were also obtained from those of the T. rubrum patient in addition to his own fungus, presumably a legacy from the previous wearer. After laundering, a few colonies of $T$. interdigitale were isolated from the socks of one of the $T$. interdigitale patients, but cultures from the other socks were negative. Thus laundering considerably reduces the quantity of potential inoculum in socks but does not eliminate it.

\section{Discussion}

When this survey was undertaken it was supposed that all the conditions making for the highest possible incidence of tinea pedis would be present. In fact, the average incidence of all dermatophytes, $39 \%$, was lower than that in miners in one of the pits investigated by Gentles and Holmes (1957) $(57 \%)$ and also than that in pits in the Ruhr (69\%) (calculated from Götz et al., 1965). However, the incidence in lodge 1 of the hospital $(66.6 \%)$ was significantly higher than that in other lodges and of the same order as that in miners. It may be, 
therefore, that conditions in lodge 1 were such that a near maximum level of infection had been reached and that, left unchecked, the same level would eventually be attained throughout the hospital. In view of the coincidence of the figures for patients in lodge 1 and of those for miners it is possible that the number of persons remaining uninfected, $30-40 \%$, represents the proportion of persons in the adult male population who are resistant to tinea pedis. The nature of this resistance is a matter of speculation (Munro-Ashman and Clayton, 1962), on which this survey throws no light; but so high a figure would explain the great difficulty found by workers who have tried to establish experimental infections in human feet (Baer, Rosenthal, Rogachefsky, and Litt, 1955; Strauss and Kligman, 1957).

Some interesting aspects of the epidemiology of the two dominant fungal species are brought out by this survey. That there was no statistically significant difference in the incidence of $T$. interdigitale in the different lodges suggests that the fungus had been present for a long period, probably with repeated introductions, leading to an even spread throughout the community. The instability of the $T$. interdigitale isolates in culture prevented any speculation over the introduction of different strains of that fungus. The T. rubrum isolates, however, were not only stable on subculture but were almost all of the same distinctive type, intermediate between the wellrecognized "granular" and "downy" forms, a type rarely found in diagnostic practice in the district (English, 1964). This suggests a single introduction at some time in the past which spread through the community, possibly followed by more recent introductions of other forms which have not yet had time to spread. The idea of early, multiple introductions of $T$. interdigitale but a single, more recent introduction of T. rubrum is compatible with knowledge of the relative incidences of the two species in the population at large (see introduction) and with the fact that $T$. rubrum has only recently reached even its present incidence in this country.

Patients in the closest contact with the original case of $T$. rubrum infection would be likely to become infected before those less close, and, once infected, their condition would not regress spontaneously. Therefore, supposing that there had not yet been time for all susceptible patients to have contracted the disease, the original introduction would have occurred in the lodge with the highest infection rate. This is lodge 7 , the only one in which both the $T$. rubrum infection rate and the $T$. rubrum $/ T$. interdigitale ratio were significantly higher than in all other lodges. T. rubrum infections in lodge 7 were also clinically more extensive and conspicuous than elsewhere (this being the lodge that originally drew the attention of R. R.W. to the problem of tinea pedis in the hospital), and were therefore likely to have been established longer, as was confirmed by the abnormally high incidence of $T$. rubrum onychomycosis in this lodge compared with an average incidence of $T$. interdigitale nail infections.

Cross-infection in the hospital must obviously have occurred by a number of routes. Within lodges it would have taken place in the dormitories, where the patients were often barefooted. Scissors used for cutting the patients' nails might also be implicated, though these were not examined. But if the bulk of the T. rubrum infections were indeed the result of a single introduction, these must also have been spread between lodges. This could partly be accounted for by the transfer of patients from lodge to lodge and also, between groups of lodges, by the sharing of bathrooms up to 1964, though the latter effect must have been comparatively slight as no statistical significance could be shcwn. As well as being probably of minor importance generally, neither of these two routes accounts for the fact that, out of nine crippled patients who had never walked, four had tinea pedis. Broughton (1955) has shown that dermatophyte fungi can be isolated from the socks of infected persons both before and after laundering, and we have confirmed this. It seems probable that the custom in this hospital of the communal ownership of socks and towels must have been an important factor in the spread of tinea pedis: in fact, if the high incidence of infection in crippled patients is any guide, it was probably the most important route between lodges. Though Broughton (1955) and Sanderson and Sloper (1953) suggest that socks are a likely means of cross-infection, our observations are probably the first to offer strong evidence that this was so in a particular community.

\section{Summary}

The incidence of tinea pedis, including tinea unguium, in a long-stay hospital for mentally retarded men was $40.8 \%$ of 358 men examined. Of the infections, $50 \%$ were attributable to Trichophyton interdigitale, $26 \%$ to $T$. rubrum, $0.7 \%$ to Epidermophyton floccosum, $4.1 \%$ (nails only) to nondermatophytes, $11.7 \%$ to mixed infections, and $7.5 \%$ were microscopically positive but cultures failed.

The incidence of $T$. rubrum was significantly higher in patients in one of the "lodges" into which the hospital was divided than in the others, but there was no significant difference in the incidence of $T$. interdigitale infections in lodges. Infection was related to the length of the patient's stay in hospital but not to his age, the communal bathroom used by him, or other factors examined. Four out of nine crippled patients who had never walked had tinea pedis. The appropriate fungus was isolated before laundering from the worn socks of three patients with $T$. interdigitale infection and of one patient with $T$. rubrum infection; after laundering the fungus was recovered from the socks of one of the patients with $T$. interdigitale infection.

In view of the failure of laundering to eliminate the fungus from worn socks, of the fact that socks were not the property of patients but were reissued indiscriminately after laundering, and of the high infection rate in patients who had never been able to walk, it is suggested that infected socks were a more important route of cross-infection in this community than contaminated floors.

We are indebted to Dr. R. P. Warin, Bristol General Hospital, for initiating this survey and for his suggestions and encouragement throughout. Our thanks are due to Dr. T. C. Leahy for allowing us access to the hospital and for putting every facility for the investigation at our disposal ; to the nursing staff of the hospital for their invaluable co-operation and interest; to Mr. T. G. Morgan, who carried out a great deal of the laboratory work; and to Dr. M. M. Walshe and Dr. R. Heeler for assistance in taking the scrapings.

\section{REFERENCES}

Baer, R. L., Rosenthal, S. A., Rogachefsky, H., and Litt, J. Z. (1955). Broughton R H (1955), Brit 7 .

English, M. (1962).

English, M. P. (1962). Ibid., 74, 50

(1964). Sabouraudia, 3, 205.

and Gibson, M. D. (1959a). Brit. med. f., 1, 1442. (1959b). Ibid., 1, 1446 and Duncan, E. H. L. (1960). Ibid., 2, 573. and and Warin, R. P. (1961). Ibid., 1, 1083.

Gentles, J. C. (1957). Brit. med. f., 1, 746. Derm., 69, 311.

Gip and Holmes, J. G. (1957). Brit. f. industr. Med., 14, 22

Gip, L. (1966). Acta derm.-venereol. (Stockh.), 46, Suppl. No. 58. otz, H., and Hantschke, D. (1965). Hautarst, 16, 543.

Sturde, H.-C., and Hantschke, D. (1965). Dermatologica (Basel),

Marples, M. J., and di Menna, M. E. (1949). Med. F. Aust., 2, 156. 551.

Partridge, B. M. (1952). Trans. St. Fohn's Hosp. derm. Soc. (Lond.), 31, Polemann, G. (1955). Arch. klin. exp. Derm., 201, 24.

Rosenthal, S. A., Baer, R. L., Litt, J. Z., Rogachefsky, H., and Furnari, Rosman, N. (1966). Brit. F. Derm., 78, 208.

Sanderson, P. H., and Sloper, J. C. (1953). Ibid., 65, 252.

Strauss, J. S., and Kligman, A. M. (1957). Ibid., 65, 252

Svendsen, I. B. (1961). Acta derm.

Svendsen, I. B. (1961). Acta derm.-venereol. (Stockh.), 41, 150.

Tritsmans, E., and Vanbreuseghem, R. (1955). Belg. Geneesk., 11, 625.

Wrede, E. (1965). Mykosen, 8. 66. (1966). Brit. F. Derm., 78, 198. 